\title{
Solution Diffusion Modeling of a Composite PVA/Fumed Silica
}

\section{Ceramic Supported Membrane}

\author{
Mohammad Samei ${ }^{1}$, Mona Iravaninia ${ }^{1}$, Toraj Mohammadi ${ }^{1, *}$, Amir Atabak Asadi ${ }^{2}$ \\ 1- Research Centre for Membrane Separation Processes, Chemical Engineering Department Iran University of Science and \\ Technology (IUST), Narmak, Tehran, Iran
}

2- Petroleum Refining Technology Development Division, Research Institute of Petroleum Industry (RIPI), Tehran, Iran

* Tel: +98 21 77240496, Fax: +98 2177240495

torajmohammadi@iust.ac.ir

\begin{abstract}
The permeation behavior of thin films of fumed silica loaded polyvinyl alcohol (PVA) coated over tubular porous ceramic supports were investigated. Mullite based support enhances mechanical strength of PVA membranes. Effects of temperature, fumed silica loading and active layer thickness on the permeation behavior of the prepared membranes were studied in terms of permeation flux and water selectivity. Experimental data were obtained by dehydration of 90 wt. \% ethanol using pervaporation (PV). The privileges of the synthesized membrane to its rivals, superior permeation flux (0.05 to $2.92 \mathrm{~kg} / \mathrm{m}^{2} \mathrm{~h}$ ), water selectivity (3 to 180 ) and pervaporation separation index (PSI) (5.84 to 82.81) along with its low manufacturing costs, let it have a potential to be used for dehydrated ethanol production in industrial scale. A solution diffusion based mathematical model, including surface exchange and bulk diffusion resistances, was developed to predict permeation flux of both components as functions of temperature, fumed silica loading, active layer thickness and feed composition. Results showed that permeation flux enhances with temperature, fumed silica loading and diminishes with membrane thickness. Besides, increasing temperature and fumed silica loading reduces selectivity while increasing membrane thickness increases selectivity.
\end{abstract}

Keywords: Solution diffusion, Mathematical modeling, Pervaporation, Composite membranes. 


\section{Introduction}

Ordinary distillation cannot be used to purify Ethanol-Water solution beyond 95.6 vol\%. Further ethanol purification could be performed by desiccation using absorbents or azeotropic and extractive distillation. Notwithstanding successes these ethanol purification techniques achieved, they all have their own disadvantages. Azeotropic distillation performance diminishes by presence of third component as an impurity and has high energy consumption [1-5]. Pervaporation (PV) separation of azeotropic solutions such as Ethanol-Water has attracted more attentions due to its lower energy consumption and higher performance in recent decades. Despite the benefits of PV, it is not the most widely used process due to the lack of suitable membrane which simultaneously possesses high permeation flux, selectivity and durability in tough operating conditions $[6,7]$. Zeolitic and polymeric membranes are two major types used for pervaporation dehydration of ethanol. Zeolite membranes have high selectivity, permeation flux and physical stability, but they are expensive, hard to prepare and sensitive to thermal tensions. On the other side, polymeric membranes are not sensitive to thermal tensions but unfortunately they exhibit low permeabilities and poor physical stabilities. Composite membrane of a polymeric active layer on a porous ceramic support gathers desirable characteristics of these two major types in one membrane [8-11]. Some studies on pervaporation performance of composite membranes prepared from a polymeric active layer on a ceramic support is summarized in Table 1. 
Table 1: Composite membranes prepared from a polymeric active layer on a ceramic support applied in pervaporation

\begin{tabular}{|c|c|c|c|}
\hline $\begin{array}{l}\text { Polymeric } \\
\text { Active Layer }\end{array}$ & Ceramic Support & Feed & Reference \\
\hline PDMS & $\mathrm{ZrO}_{2} / \mathrm{Al}_{2} \mathrm{O}_{3}$ & Ethanol-Water & [12] \\
\hline PDMS, PVA and chitosan & $\begin{array}{l}\text { Commercialized macroporous } \\
\text { ceramic supports }\end{array}$ & bio-fuels & [13] \\
\hline PDMS & $\mathrm{ZrO}_{2} / \mathrm{Al}_{2} \mathrm{O}_{3}$ & Ethanol-Water & [14] \\
\hline PDMS & $\mathrm{ZrO}_{2} / \mathrm{Al}_{2} \mathrm{O}_{3}$ & Ethanol-Water & [15] \\
\hline Silicone rubber & Silicalite membranes & Ethanol-Water & [16] \\
\hline PDMS & ceramic supports & n-octane/thiophene & [17] \\
\hline PDMS & ceramic supports & Isopropanol-Water & [18] \\
\hline PVAc and PVP & $\begin{array}{l}\text { vinylsilane-modified alumina } \\
\text { substrate }\end{array}$ & $\begin{array}{l}\text { Methanol-Methyl } \\
\text { tert-butyl ether } \\
\text { (MTBE) }\end{array}$ & [19] \\
\hline PVA & $\mathrm{ZrO}_{2} / \mathrm{Al}_{2} \mathrm{O}_{3}$ & Ethyl acetate-Water & [20] \\
\hline PVAc & porous tubular silica substrate & $\begin{array}{l}\text { Trichloroethylene } \\
\text { and chloroform- } \\
\text { Water }\end{array}$ & [21] \\
\hline
\end{tabular}

Selectivity and permeation flux through polymeric membranes are strong functions of the membrane composition, preparation method, membrane thickness and operating conditions such as temperature, components partial pressure gradient across the membrane $[6,22]$. As experimental evaluation of the membrane permeation behavior is time and money consuming, the need for an accurate and simple model is rising. Furthermore, a precise model plays a crucial rule in pervaporation scale up. Many researchers [23-30] attempted to model permeation behavior of polymeric membranes. Transport model through dense membranes are based on irreversible processes thermodynamics [31], Maxwell-Stefan theory [32] and Fick's law [33]. Applying these models to pervaporation process and considering possible transport mechanisms result in five main categories of models including, solution-diffusion 
model, pore flow model, thermodynamic vapor liquid equilibrium model, pseudo phase change solution-diffusion models and dusty gas model.

Considering solution-diffusion model which is the most widely accepted one for pervaporation; this process could be described in four sequential steps, feed side bulk diffusion, membranes feed side superficial sorption, diffusion through the membrane and membranes permeate side superficial desorption [34]. The main governing steps are feed side sorption and diffusion trough the membrane. In pore flow model, the membrane was assumed as a microporous layer [35]. The third model is thermodynamic vapor liquid equilibrium model in which pervaporation process was described as vapor sorption and diffusion through the membrane [36]. It is assumed that the vapor is in equilibrium with feed. In addition, it is assumed that the sorption step is governed by Henry's law and the diffusion coefficient is constant. Due to these assumptions this model could only be used over small range of feed concentrations where the mentioned suppositions are acceptable. Extending the solutiondiffusion model for vapor and liquid flows through the membrane, and considering the fact that phases change occur gradually inside the membrane body, beside taking into account the pressure variation across the membrane, pseudophase-exchange solution-diffusion model developed which is similar to pore flow model [37]. Since the governing transport mechanism through zeolite and polymeric membranes are different, which could be attributed to the strong superficial forces inside the zeolite pores, Karger et al. proposed dusty gas model based on diffusion of a phase formed from adsorbed molecules, called intra crystalline diffusion [38].

Pervaporation models usually have insufficiencies in predicting the pervaporation behavior of non-ideal systems such as alcohol-water-PVA mixtures. This issue could be attributed to the strong hydrogen bounding and swelling effects [39]. It even become more challenging to model a pervaporation system with PVA based composite membranes. Researchers tried to 
develop new models and test existing ones, but despite their efforts there are still some weaknesses.

The purposes of this paper are studying preparation of a new, high performance PVA composite membrane and developing a simple and accurate solution-diffusion based model to explain permeation behavior of the polymeric-ceramic composite membranes. To fulfill this, a thin high-permselective polymeric layer was coated over a tubular porous ceramic support and the synthesized membranes were used in ethanol dehydration. PVA membranes have number of weaknesses, including low permeability and insufficient mechanical strength. To increase membrane permeability, it should be prepared as thin as possible and thus as mentioned, it is necessary to be supported mechanically. A porous ceramic MF membrane was used as support to enhance mechanical strength of thin PVA membrane and thus the PVA active layer could be prepared as thin as possible. Consequently, higher permeabilities and PSI values were obtained. In addition, tubular membrane configuration provides higher surface per volume and thus membrane module size for specific separation reduces [40-42].

\section{Experiments}

\subsection{Materials}

PVA (MW: 145,000) with a degree of hydrolysis of more than 98\%, ethanol 96\%, glutaraldehyde (GA, 50\%) and hydrochloric acid were all purchased from Merck. Aerosil 200 was purchased from Evonika Co. with particle size of $12 \mathrm{~nm}$, surface area of $200 \mathrm{~m}^{2} / \mathrm{g}$, density of $50 \mathrm{gr} / \mathrm{lit}$, and purity of higher than $99.9 \%$. Kaolin powder was supplied by IRAN China Clay Industries Co. Deionized water, with a conductivity of $20 \mu \mathrm{S} / \mathrm{cm}$, was produced in the laboratory using Permionics pilot plant (Vadodara, India). 


\subsection{Membrane preparation}

Firstly, the kaolin clay was suspended in deionized water and allowed to settle inside its container. After removal of the upper clear water, a homogeneous mud was obtained. Tubular membranes were then prepared by extrusion of the aged uniformed mud. After an overnight drying of extrudats at room temperature, sintering was performed at $1200{ }^{\circ} \mathrm{C}$ for $3 \mathrm{~h}$, with a heating and cooling rate of $1{ }^{\circ} \mathrm{C} / \mathrm{min}$. The prepared ceramic support had average pore radius of $318.2 \mathrm{~nm}$ and porosity of $30.45 \%$. Complete preparation procedure and characterizations of mullite tubular microfiltration supports were reported in our previous work [43]. Homogeneous coating solution was obtained by dissolving PVA in deionized water at $90{ }^{\circ} \mathrm{C}$ and stirred for a while. It must be noted that duration of stirring depends on the solution concentration. Various amount of fumed silica were introduced to the solution. In situ crosslinking was performed by adding GA and hydrochloric acid to the solution and continuous stirring for $1 \mathrm{~h}$. After homogenization and degasification, the solution was ready to be coated on the ceramic support. While the ceramic support was slowly (60 rpm) spun, the outer surface was coated with the PVA solution and dried. Afterward, the coating process was repeated again. After drying for $24 \mathrm{~h}$ at room temperature, complete drying and crosslinking were performed in an electric oven at $110{ }^{\circ} \mathrm{C}$ for $1 \mathrm{~h}$. Membrane preparation procedure was described in details elsewhere [42].

\subsection{Pervaporation Experiments}

The prepared membranes were evaluated in PV dehydration of ethanol-water (90/10) mixture at different temperatures using a setup shown in Figure 1. The effective membrane area was $132 \mathrm{~cm}^{2}$. The downstream pressure was controlled to be $12 \mathrm{~mm} \mathrm{Hg}$, while the feed pressure was atmospheric. To establish the steady-state conditions, before performing the PV measurements the membrane was swelled in the feed for $2 \mathrm{~h}$. The permeate sample collected 
in a cold trap was weighed to determine the permeation flux. To eliminate the experimental errors, each test was repeated three times, and the average results were reported.

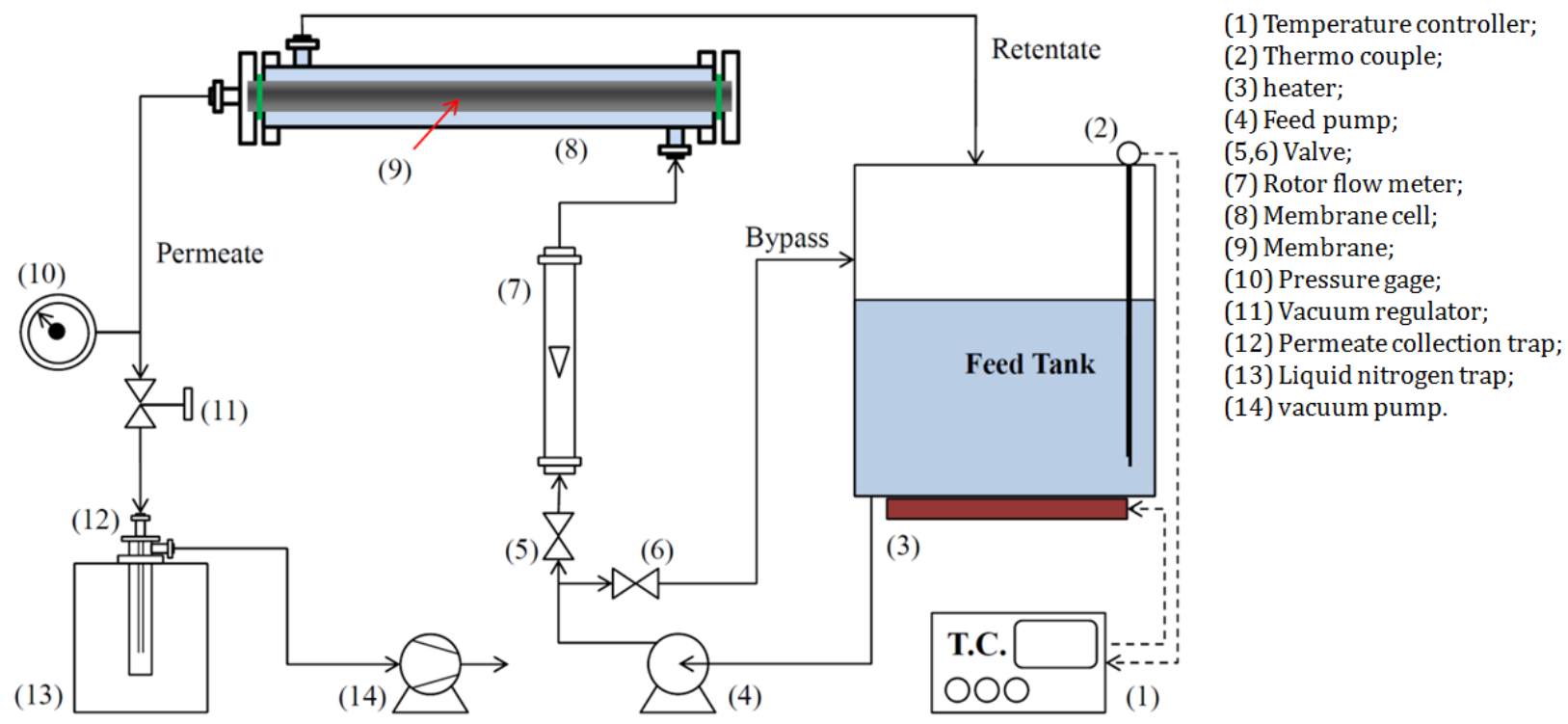

Fig. 1: Schematic diagram of the PV apparatus

Permeation properties of the membranes were characterized by PV selectivity $\left(\alpha_{\mathrm{PV}}\right)$, total permeation flux $\left(\mathrm{J}_{\mathrm{P}}\right)$ and PV separation index (PSI) defined as the following equations, respectively $[44,45]$ :

$\alpha_{P V}=\frac{y_{A} / y_{B}}{x_{A} / x_{B}}$

$J_{P}=\frac{Q}{A \times \Delta t}$

$P S I=J_{P} \times\left(\alpha_{P V}-1\right)$

Where $y_{A}$ and $y_{B}$ are mass fractions of water and ethanol in the permeate, respectively and $\mathrm{x}_{\mathrm{A}}$ and $\mathrm{x}_{\mathrm{B}}$ are mass fractions of water and ethanol in the feed, respectively. The permeate flux, $J_{P}\left(\mathrm{~kg} / \mathrm{m}^{2} \mathrm{~h}\right)$, was calculated using $\mathrm{Q}$; the permeate mass $(\mathrm{kg}), \mathrm{A}$; the effective membrane area $\left(\mathrm{m}^{2}\right)$ and $\Delta \mathrm{t}$; the permeation time $(\mathrm{h})$. 


\section{Model development}

Basis of pervaporation is preferential permeation of liquid mixture components and removal of species in the permeate side as vapor using partial vacuum. A schematic pervaporation membrane and profiles of pressure, chemical potentials and activities of a binary solution are illustrated in Figure 2. Obviously, three phases of feed, membrane and permeate can be indicated. As clearly observed, chemical potentials of both components varies along the membrane.

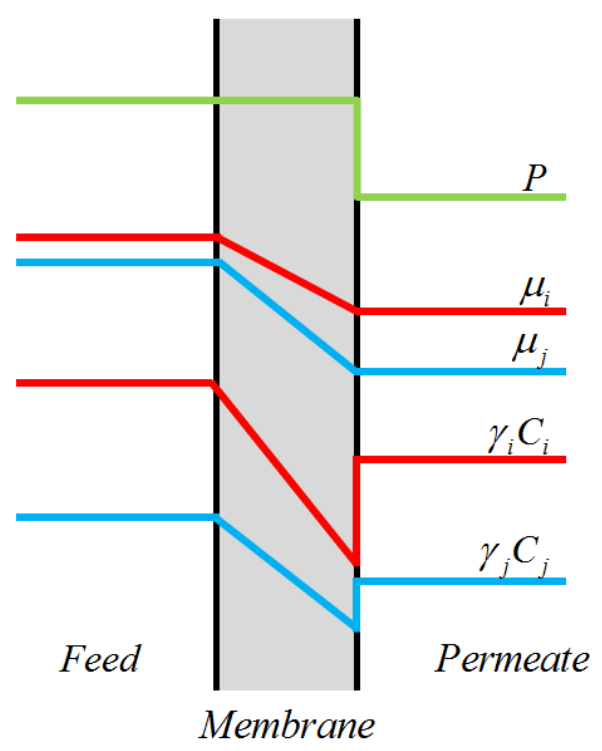

Fig. 2: Schematic PV membrane and profiles of pressure, chemical potentials and activities of a binary solution

For feed and membrane phases, chemical potentials were formulated using equation (4) while equation (5) was used for permeate phase [46].

$$
\begin{aligned}
& \mu_{i}=\mu_{i}^{0}+R T \ln \left(\gamma_{i} c_{i}\right)+v_{i}\left(p-p_{i_{s a t}}\right) \\
& \mu_{i}=\mu_{i}^{0}+R T \ln \left(\gamma_{i} c_{i}\right)+R T \ln \left(\frac{p}{p_{i_{s a t}}}\right)
\end{aligned}
$$

In these two equations, chemical potential of pure species $i$ at saturation pressure of $p_{i_{s a t}}$ is indicated as $\mu_{i}^{0} . c_{i}$ and $\gamma_{i}$ are molar concentration and activity coefficient of species $i$, 
respectively. Considering much higher absorption and desorption rates at the membrane interfaces compared to diffusion rate through the membrane, equilibrium at the either membrane interfaces can be assumed. Besides, it is assumed that pressure remains equal to the feed side pressure within the membrane and chemical potential through the membrane is expressed as concentration. Chemical potential gradient is driving force of species transported through the membrane, thus permeation flux can be formulated as equation (6).

$$
J_{i}=-L_{i} \frac{d \mu_{i}}{d x}
$$

By introducing chemical potential into equations (4) and (5), and using equation (6), $J_{i}$ can be written as:

$$
J_{i}=\frac{D_{i}\left(c_{i_{o(m)}}-c_{i_{l(m)}}\right)}{l}
$$

Molar concentration of species $i$ in the membrane at the feed side interface $\left(c_{i_{o(m)}}\right)$ and the permeate side interface $\left(c_{i_{l(m)}}\right)$ can be calculated using equations (8) and (9), respectively. In $c_{i_{(m)}}$ and $c_{i_{l(m)}}, o$ and $l$ stand for feed and permeate sides, respectively. These equations are based on the equal chemical potential of each species in the feed and permeate solutions with the chemical potential of that species in the membrane body at the adjacent interface [46].

$$
\begin{aligned}
& c_{i_{o(m)}}=\frac{\gamma_{i_{o}} c_{i_{o}}}{\gamma_{i_{o(m)}}}=K_{i} \times c_{i_{o}} \\
& c_{i_{l(m)}}=\frac{\gamma_{i_{l}} c_{i_{o}}}{\gamma_{i_{o}(m)}} \times \frac{p_{l}}{p_{i_{s a t}}}=\frac{\gamma_{i_{l}}}{\gamma_{i_{o(m)}}} \times \frac{p_{i_{l}}}{p_{i_{s a t}}}=K_{i}^{G} \cdot p_{i_{l}}
\end{aligned}
$$

In these equations, $K_{i}$ and $K_{i}^{G}$ are liquid and gas phase sorption coefficients of species $i$, respectively. Considering a hypothetical vapor in equilibrium with feed solution, equation (8) can be written as; 
$c_{i_{o(m)}}=\frac{\gamma_{i_{o}}^{G}}{\gamma_{i_{o(m)}}} \times \frac{p_{i_{o}}}{p_{i_{s a t}}}=K_{i}^{G} \cdot p_{i_{o}}$

Combining equation (7), (9) and (10) and considering $P_{i}^{G}=K_{i}^{G} \cdot D_{i}$ gives

$J_{i}=\frac{P_{i}^{G}}{l}\left(p_{i_{o}}-p_{i_{l}}\right)=\frac{P_{i}^{G}}{l}\left(\frac{c_{i_{o}} \cdot \gamma_{i_{o}}^{L} \cdot P_{i_{s a t}}}{\gamma_{i_{o}}^{G}}-p_{i_{l}}\right)=\frac{P_{i}^{G}}{l}\left(c_{i_{o}} \cdot H_{i}-p_{i_{l}}\right)$

Equation (11) is the basic solution diffusion model which governs permeation behavior of a dense neat polymeric membrane. A membrane consists of a single neat polymer acts like a single phase which is in equilibrium with feed phase and permeate phase as assumed in solution diffusion basis assumptions [46]. However, for a membrane which is not a single phase, conditions are different. Presence of fumed silica in the polymeric membrane body and its hydrophilic nature result in higher water fraction in the polymer layer adjacent to these particles, and this leads to formation of much more swollen layer of polymer around the fumed silica particles during pervaporation tests due to tremendous water absorbed by these particles. Presence of these highly swollen regions throughout the membrane body affects its permeation behavior and cannot accurately model using solution diffusion theory [41, 47, 48]. Therefore, some modifications should be performed on the basic solution diffusion model. Since these two phases present both on the membrane surface and inside the membrane body, sorption and diffusion properties of the membrane are affected by their intrinsic properties. Clearly, sorption and diffusion properties of the whole composite membrane should be functions of amounts of these two phases and also the fumed silica loading. Two main parameters are affected by fumed silica loading, $H_{i}$; Henry law coefficient and $P_{i}^{G}$; permeability of species $i$. To introduce effects of fumed silica loading on these two, two contribution coefficients were defined. Contribution coefficient of the extremely swollen polymer interface in Henry law coefficient was introduced to the model as $c c_{H_{S_{w l}}}$ 
$c c_{H_{S w l}}=\left(X_{F S}\right)^{a}$

And contribution coefficient of the extremely swollen polymer body in permeability was introduced to the model as $c c_{P_{S w l}}$;

$c c \cdot \cdot_{P_{S w l}}=\left(X_{F S}\right)^{b}$

In equations (12) and (13), $X_{F S}$ is weight fraction of fumed silica in the membrane and $a$ and $b$ are constants.

Sum of the main polymer and extremely swollen polymer contribution coefficients in both Henry law coefficient and permeability should be one. Thus, contribution coefficients of the common polymer should be:

$c c \cdot_{H_{\text {com }}}=1-\left(X_{F S}\right)^{a}$

$c c \cdot_{P_{\text {com }}}=1-\left(X_{F S}\right)^{b}$

Where $c c_{H_{\text {com }}}$ and $c c_{P_{\text {com }}}$ are contribution coefficients of the common polymer phase in Henry law coefficient and permeability of the membrane respectively. Now, Henry law coefficient and permeability of the membrane could be formulated as equation (16) and (17) respectively.

$$
\begin{aligned}
& H_{i}=c c_{\cdot_{H_{c o m}}} \times H_{i_{c o m}}+c c_{\cdot_{H_{S w l}}} \times H_{i_{S_{w l}}} \\
& P_{i}^{G}=c c \cdot_{P_{\text {com }}} \times P_{i_{c o m}}^{G}+c c \cdot_{P_{S w l}} \times P_{i_{\text {Swl }}}^{G}
\end{aligned}
$$

Equations (18) and (19) show Henry law coefficient and permeability which were defined to have Arrhenius temperature functionality [46].

$$
\begin{aligned}
& H_{i_{X}}=H_{0 i_{X}} \times e^{\frac{-E_{H, i_{X}}}{R}\left(\frac{1}{T}-\frac{1}{T_{0}}\right)} \\
& P_{i_{X}}^{G}=P_{0 i_{X}}^{G} \times e^{\frac{-E_{P, i_{X}}}{R}\left(\frac{1}{T}-\frac{1}{T_{0}}\right)}
\end{aligned}
$$


Where $H_{0 i_{X}}$ and $P_{0 i_{X}}^{G}$ are Henry law coefficient and permeability of species $i$ in the extremely swollen polymer $(X=S w l)$ or common polymer phase $(X=c o m) . E_{H, i_{X}}$ and $E_{P, i_{X}}$ are activation energies of sorption and permeation of component $i$ in the extremely swelled polymer $(x=S w l)$ or common polymer phase $(x=c o m)$.

In addition to consider effects of fumed silica content on membrane permeation performance model as contribution coefficients in permeability and Henry law coefficient, its effects was also introduced using a modified thickness called membrane effective thickness as shown in equation (20).

$l_{\text {effective }}=l \times\left(1+c \times X_{F S}{ }^{d}\right)$

In this equation, $c$ and $d$ are constants which are determined using the model. Therefore the modified model now predicts the permeation flux for any species based on the following equation;

$J_{i}=\frac{P_{i}^{G}}{l_{\text {effective }}}\left(c_{i_{o}} \cdot H_{i}-p_{i_{l}}\right)$

\section{Results and discussion}

\subsection{Characterization}

Presence of specific chemical groups in the PVA active layer of the composite membrane was studied using Fourier Transform Infrared Spectroscopy (FTIR). The active layer FTIR spectra, as presented in Figure 3, were obtained in the range of wavenumber from 4000 to $600 \mathrm{~cm}^{-1}$ during 16 scans (Bruker Equinox 55, Bruker Optics Inc., Billerica, MA, USA). 


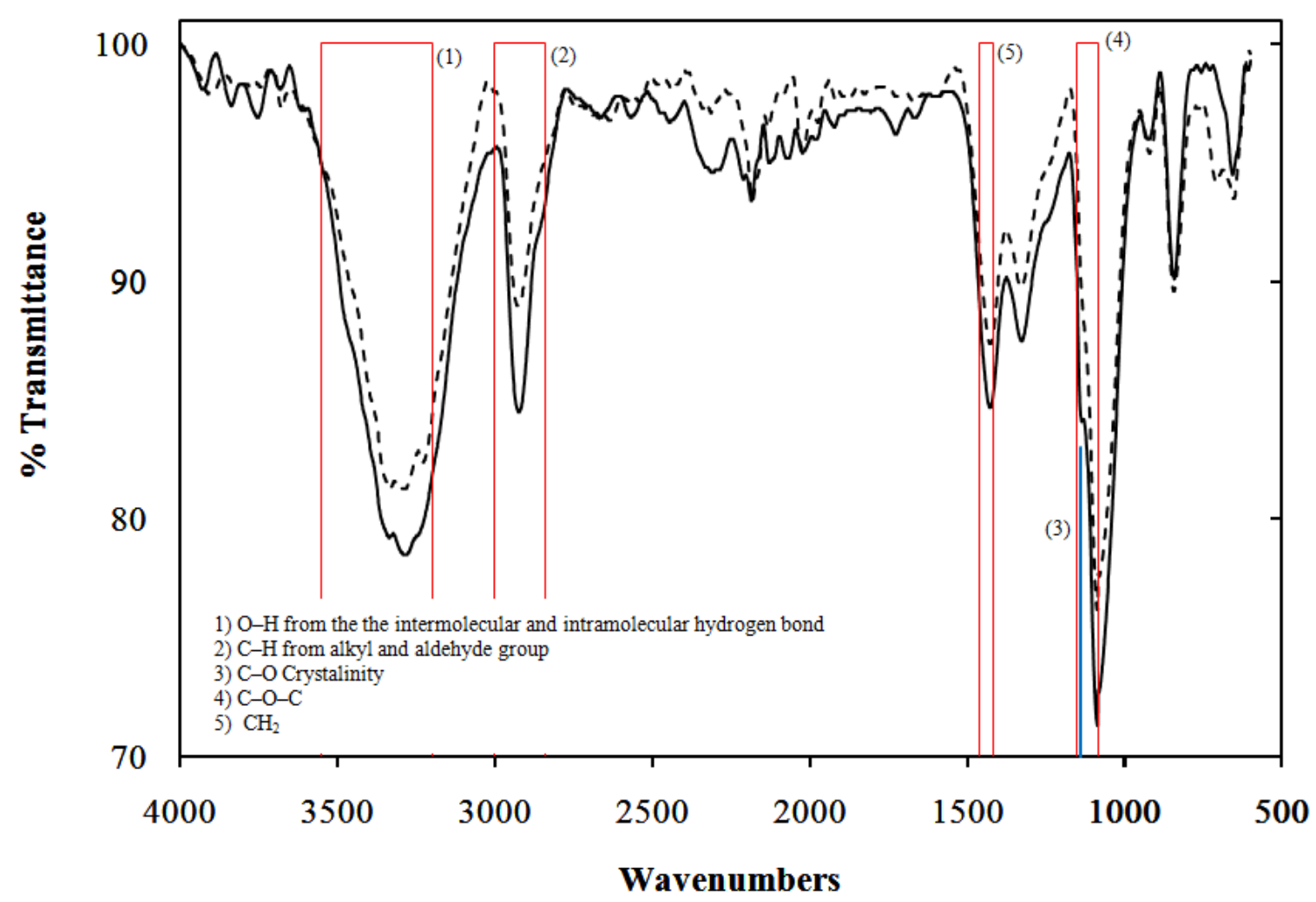

Fig. 3: non-crosslinked (dashed Line) and crosslinked (full Line) PVA layer FTIR spectra

As clearly observed, $\mathrm{O}-\mathrm{H}$ group of the intermolecular and intramolecular hydrogen bonds (3550-3200 $\left.\mathrm{cm}^{-1}\right)$ and $\mathrm{C}-\mathrm{H}$ group of the alkyl groups $\left(3000-2840 \mathrm{~cm}^{-1}\right)$ are present in the synthetic PVA layer. Reaction of PVA in the presence of GA forms acetal bridges which lead to peak intensity reduction of the crosslinked PVA O-H group compared with that of the non-crosslinked PVA. SEM micrographs of the composite ceramic-supported PVA membranes are shown in Figure 4. 


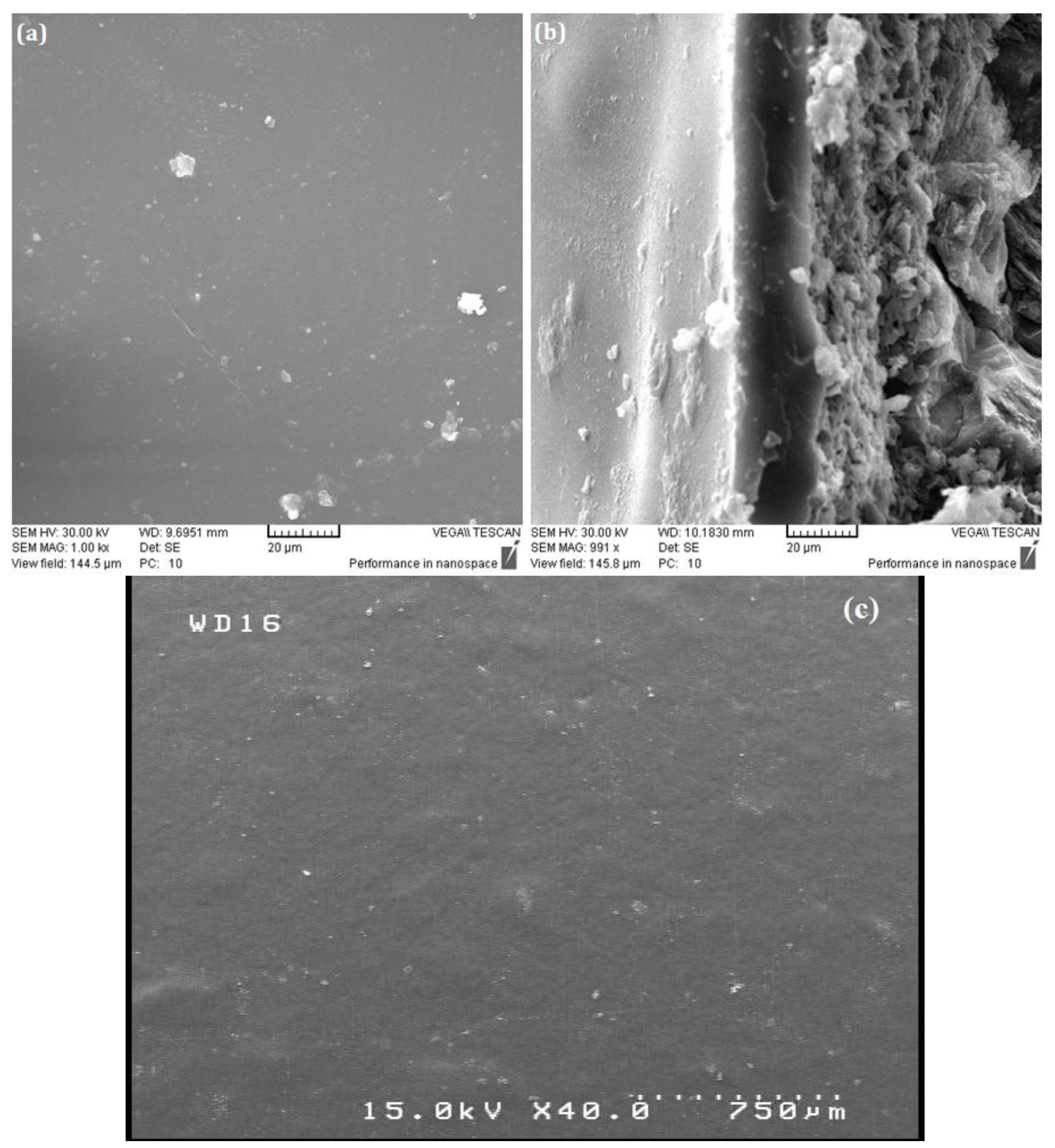

Fig. 4: SEM micrographs of membrane surface (a), cross section (b) and vast surface area (c)

From the SEM micrographs, it can be clearly observed that the PVA layers are defect free.

More details of the membrane characterization is available elsewhere [42].

\subsection{Model validation}

Nonlinear regression method was used to find the developed model parameters. Error minimization was performed while root mean square deviation (RMSD) was the objective 
function. Furthermore, square of the Pearson product moment correlation coefficient $\left(\mathrm{R}^{2}\right)$ was calculated. Parity plot between experimental and calculated data is presented in Figure 5.

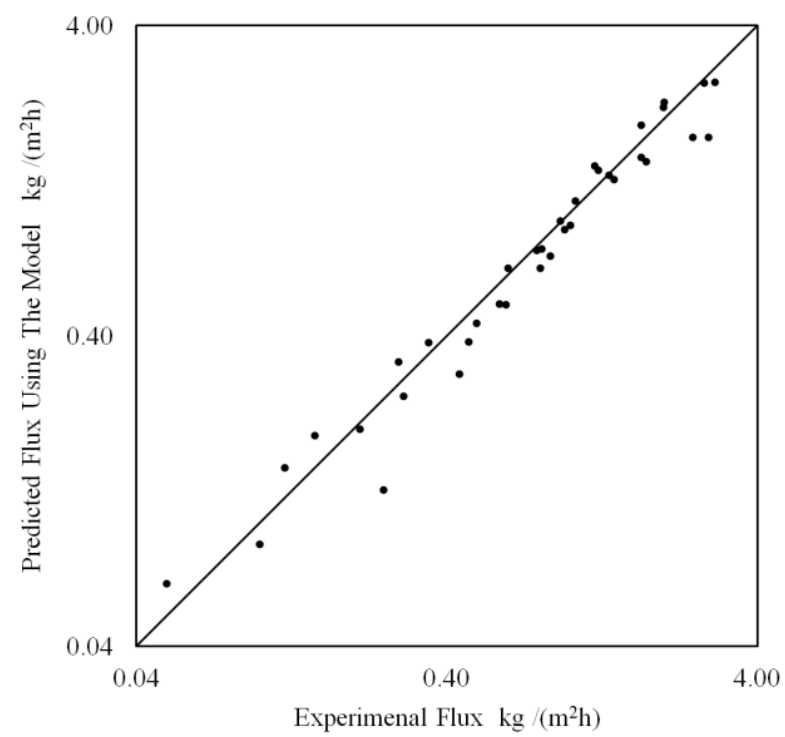

Fig. 5: Parity plot between experimental and calculated permeation flux data

As illustrated, a rather good agreement was established between experimental and calculated data. Values of activation energies, pre-exponential coefficients and contribution coefficients constants are summarized in Table 2 . 
Table 2: Model parameters

\begin{tabular}{ccc}
\hline \multirow{2}{*}{ parameters } & \multicolumn{2}{c}{ Calculated values for } \\
\hline$P_{0 i_{c o m}}^{G}$ & Water & Ethanol \\
$E_{P_{i_{\text {com }}}}$ & $-9.42 \mathrm{E}-09$ & $3.85 \mathrm{E}-10$ \\
$H_{0 i_{\text {com }}}$ & $8.58 \mathrm{E}+03$ & $-5.64 \mathrm{E}+04$ \\
$E_{H, i_{\text {com }}}$ & $3.67 \mathrm{E}+04$ & $1.45 \mathrm{E}-02$ \\
$P_{0 i_{\text {Swl }}}^{G}$ & $6.00 \mathrm{E}-07$ & $1.23 \mathrm{E}+05$ \\
$E_{P, i_{\text {Swl }}}$ & $-8.91 \mathrm{E}+05$ & $9.08 \mathrm{E}-08$ \\
$H_{0 i_{S w l}}$ & $2.94 \mathrm{E}+03$ & $-1.88 \mathrm{E}+05$ \\
$E_{H, i_{\text {Swl }}}$ & $1.70 \mathrm{E}+04$ & $7.61 \mathrm{E}+02$ \\
$\mathrm{a}$ & $1.87 \mathrm{E}+00$ & $1.40 \mathrm{E}+05$ \\
$\mathrm{~b}$ & $1.87 \mathrm{E}+00$ & $1.56 \mathrm{E}-01$ \\
$\mathrm{c}$ & $3.01 \mathrm{E}+04$ & $2.40 \mathrm{E}+00$ \\
$\mathrm{~d}$ & $3.60 \mathrm{E}+00$ & $3.15 \mathrm{E}+01$ \\
\hline
\end{tabular}

\subsection{Pervaporation}

The modified model was based on the solution-diffusion model which describes permeation through membranes by means of a thermodynamically based sorption and kinetically based diffusion. In the following parts, effects of membrane thickness, fumed silica loading and temperature on solution and diffusion terms in the proposed model are investigated.

\subsubsection{Effect of PVA layer thickness}

As seen in Figure 6, higher selectivity is achievable in pervaporation process using thicker active layer however, Figure 7 clearly illustrates that increasing membrane thickness diminishes permeation flux. This phenomenon can be related to the diffusion portion of the separation mechanism. As clearly observed in Equation (21), permeation flux of species is 
reversely proportional to membrane thickness and increasing membrane thickness results in lower permeation flux of both ethanol and water. The thicker active layer means the membrane is more defect free with less defects and this restricts ethanol permeation. This results in higher diffusion resistance establish for ethanol compared to water and in the other words selectivity increases which is in agreement with experimental results as revealed in Figure 6, however in the developed model, which is based on the solution diffusion, the membrane is assumed to be ideal and thus selectivity does not depend on membrane thickness and varies with other parameters as demonstrated in Figures 6 to 9 .
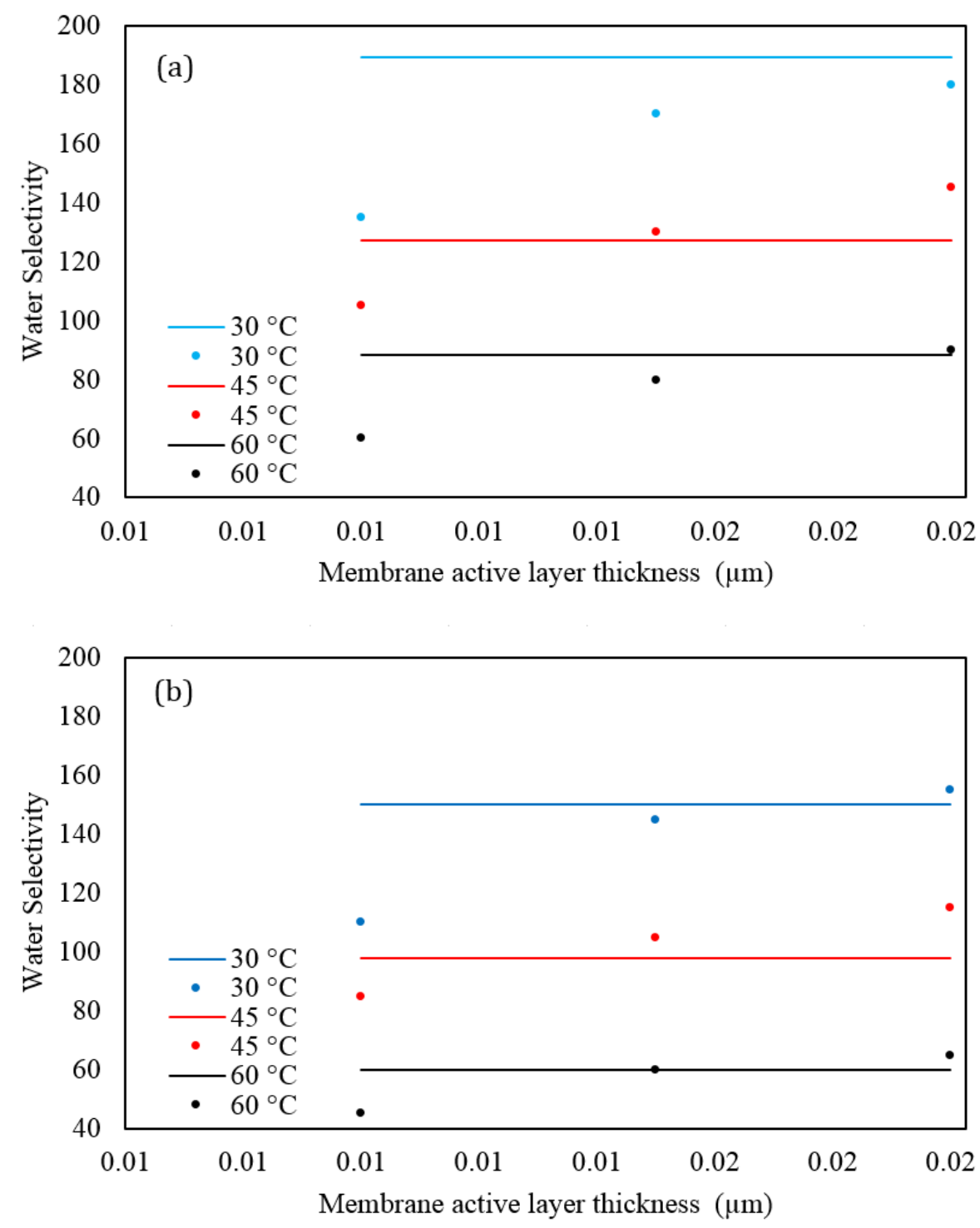
Fig. 6: Effect of membrane active layer thickness on experimental and model predicted water selectivity of pure PVA membrane (a), and 2 wt.\% silica fumed loaded PVA membrane (b)
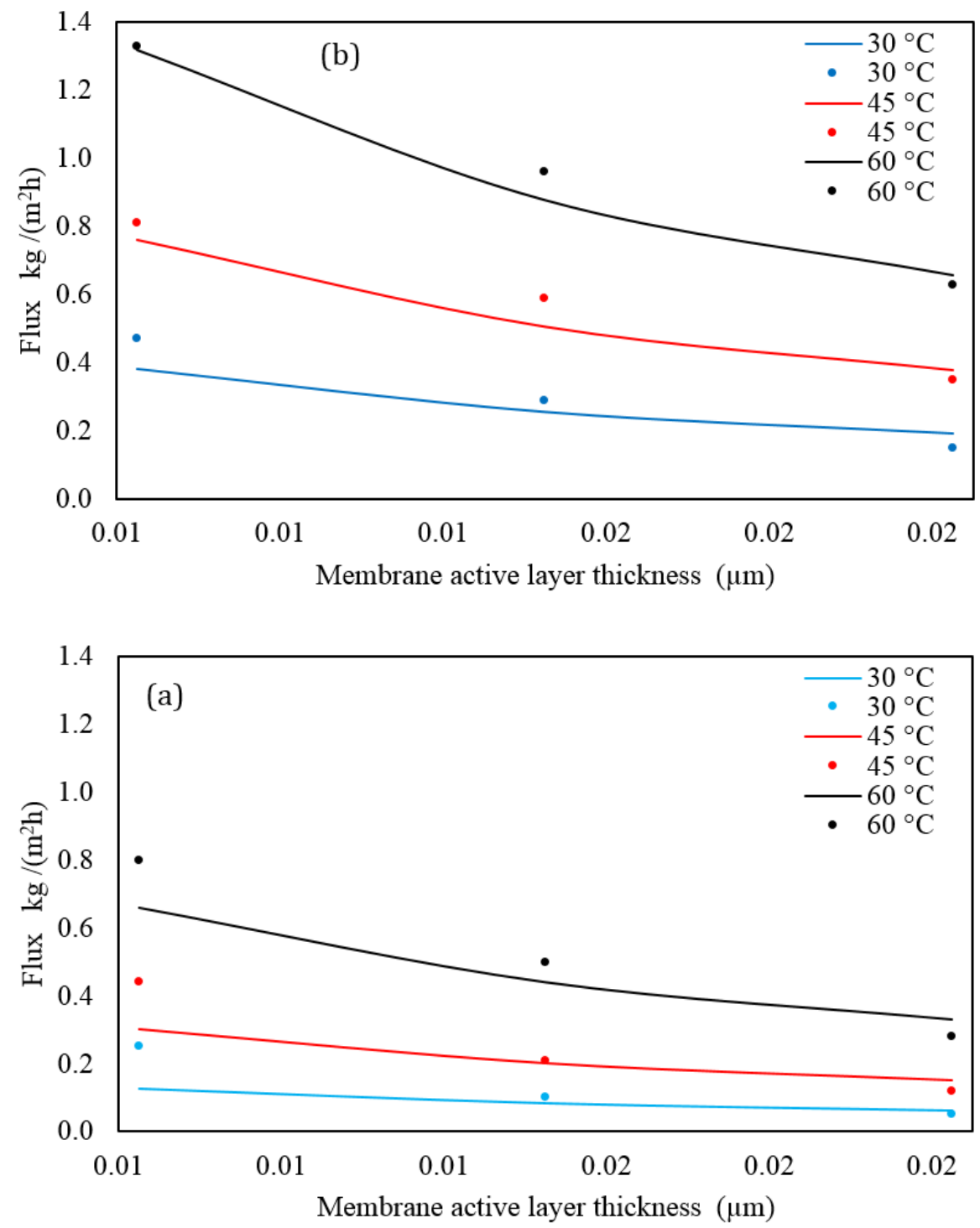

Fig. 7: Effect of membrane active layer thickness on experimental and model predicted permeation flux of pure PVA membrane (a), and 2 wt.\% silica fumed loaded PVA membrane (b)

\subsubsection{Effect of temperature}

Equations (18) and (19) formulate temperature dependencies of Henry law coefficient and permeability of species $i$ in different phases. The model proposes an Arrhenius temperature functionality of these two. Using the predicted model constants, increasing temperature reduces both water and ethanol permeability in both common and swollen polymeric 
portions. However, water permeability through common polymer and through swollen polymer are the least and the most temperature dependent permeabilities.

Water and ethanol Henry law coefficients also demonstrate an Arrhenius functionality of temperature. Henry law coefficients of water and ethanol related to the common polymer phase were calculated to be somehow equal at $30{ }^{\circ} \mathrm{C}\left(H_{E_{\text {com }}}=0.7 \times H_{W_{\text {com }}}\right)$ [49] and both increase as temperature rises. However, due to higher temperature dependency of ethanol Henry law coefficient, at temperatures around $60{ }^{\circ} \mathrm{C}$ Henry law coefficient of ethanol is about 16 times greater than that of water. In the swollen polymer portion, Henry law coefficient of water is always smaller than that of ethanol and also its temperature dependency is weaker, thus by increasing temperature Henry law coefficient of ethanol in swollen polymer becomes much more bigger than that of water.

Considering equation (17) which predicts water and ethanol permeabilities through the whole body of the membrane which consists of common and swollen polymer portions, temperature dependencies of $P_{i_{c o m}}$ and $P_{i_{s w l}}$, and model constants were evaluated. The model predicts that permeability of water through the whole body of the membrane decreases almost linearly by increasing temperature. However, the model predicted that permeability of ethanol decreases asymptotically and increasing temperature above $50{ }^{\circ} \mathrm{C}$ does not affect ethanol permeability significantly.

The model predicts that Henry law coefficients of both water and ethanol increase by rising temperature. It should be noted that water Henry law coefficient like water permeability is almost a linear function of temperature, while ethanol Henry law coefficient at temperature below $50{ }^{\circ} \mathrm{C}$ shows asymptotic behavior.

Figures 8 and 9 illustrate effects of temperature on experimental and model predicted permeation flux and selectivity of neat and fumed silica loaded PVA membranes. 

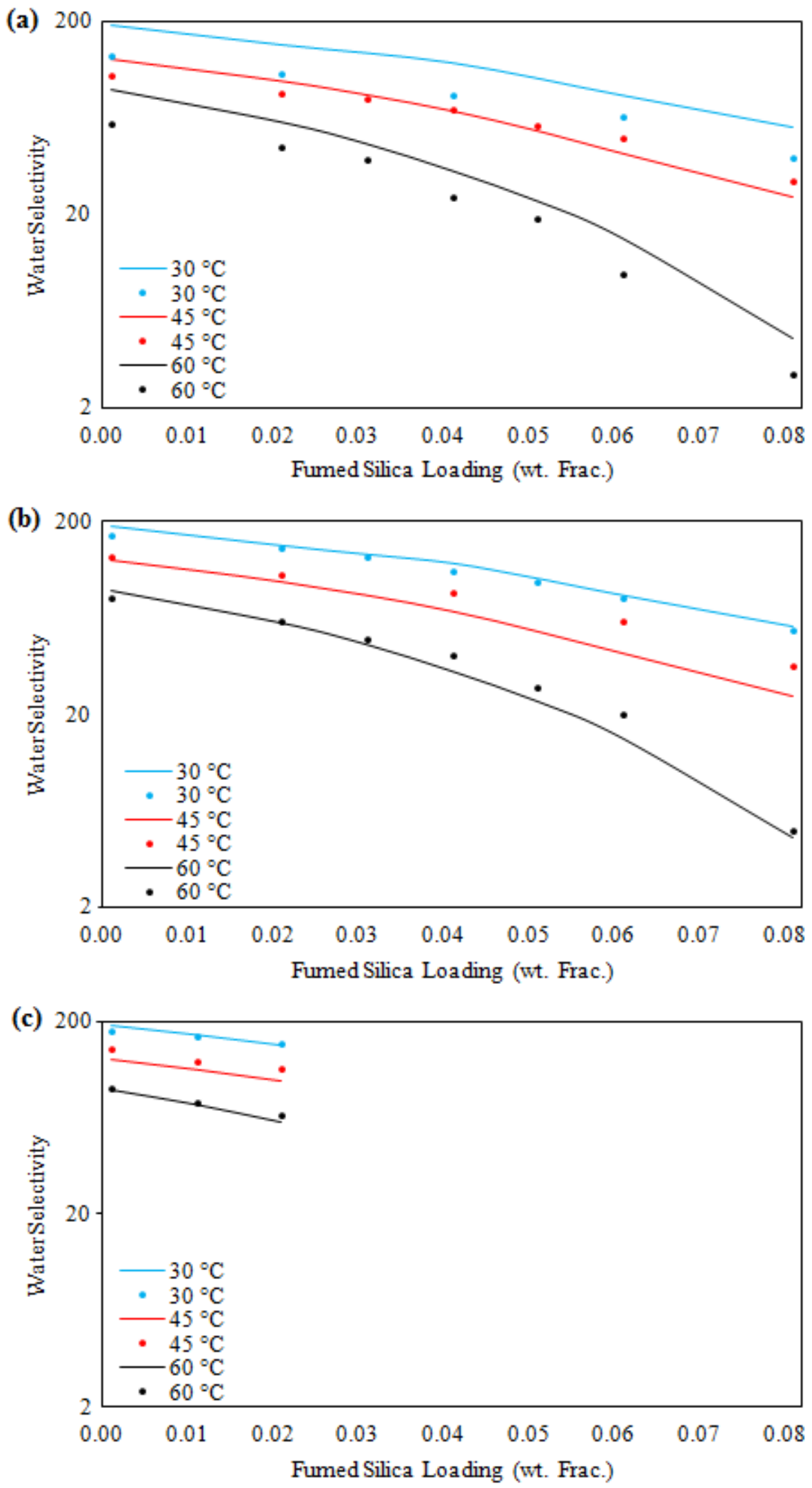

Fig. 8: Effects of fumed silica loading and temperature on experimental and model predicted water selectivity of PVA membranes with $10 \mu \mathrm{m}$ (a), $15 \mu \mathrm{m}$ (b) and $20 \mu \mathrm{m}$ (c) 

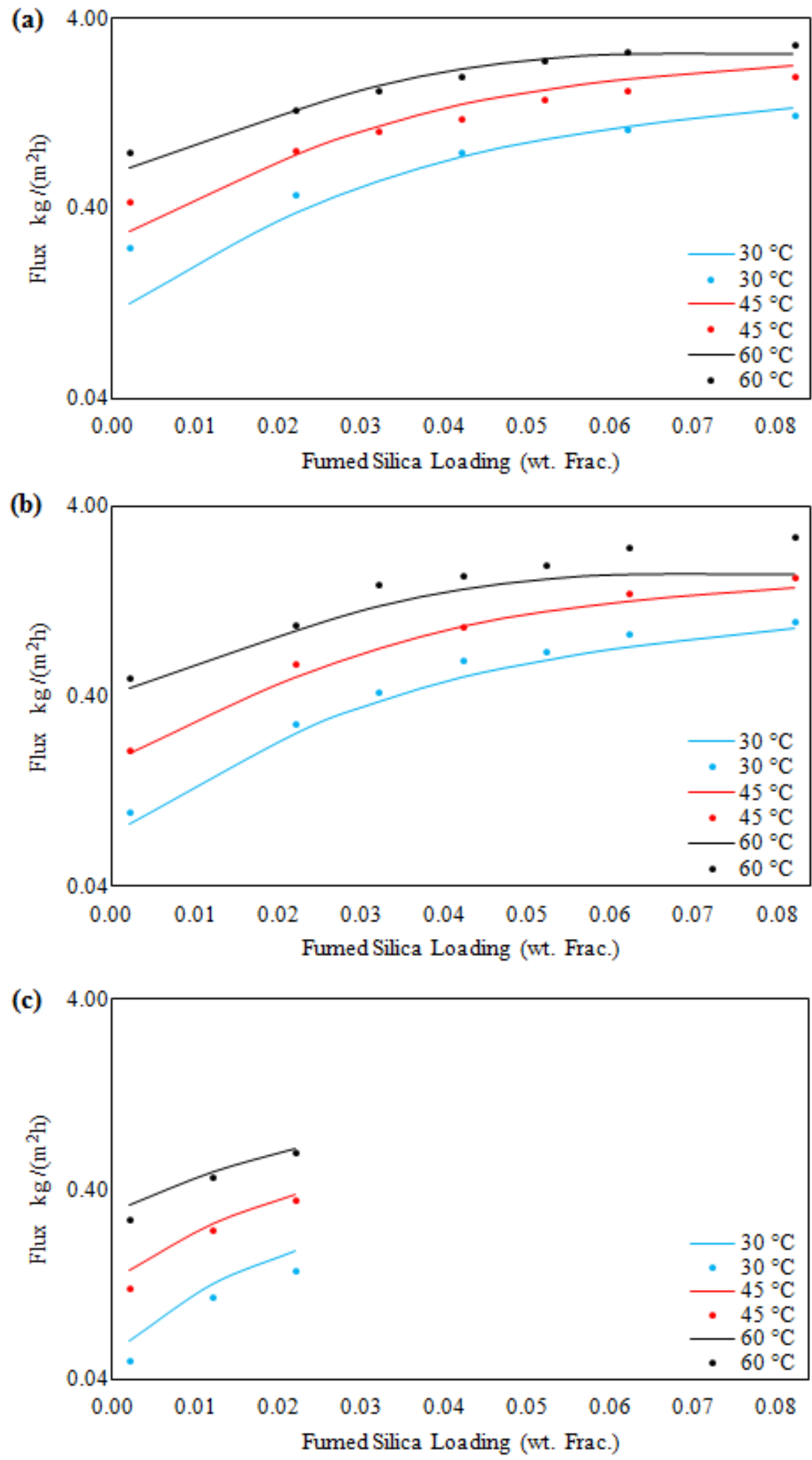

Fig. 9: Effects of fumed silica loading and temperature on experimental and model predicted permeation flux of PVA membranes with $10 \mu \mathrm{m}$ (a), $15 \mu \mathrm{m}$ (b) and $20 \mu \mathrm{m}$ (c) 
Increasing temperature enhances permeation flux, while diminishes membrane selectivity. The developed model predicts total permeation flux from water and ethanol permeation fluxes. As predicted by the model, water and ethanol permeation fluxes in common polymeric portion increases with increasing temperature, while their fluxes through swollen polymeric portion of the membrane behave differently. By increasing temperature, ethanol permeation flux increases, while water permeation flux through the membrane increases within the temperature range for membranes containing $0,2,4$ and 6 wt. $\%$ of fumed silica, however for membrane loaded with 8 wt.\% of fumed silica, water permeation flux increases up to its maximum value at about $45^{\circ} \mathrm{C}$ and afterward, decreases significantly.

\subsubsection{Effect of fumed Silica loading}

From the data presented in Figures 8 and 9, it is observed that permeation flux increases, and membrane selectivity decreases with increasing fumed silica loading throughout the studied temperature range. Permeability and Henry law coefficients of water and ethanol in common and swollen polymeric portions of the membrane are independent on fumed silica loading. However, permeability and Henry law coefficients of both species through the membrane are related to fumed silica loading via equations (16) and (17). Water permeability varies less than $1 \%$ when fumed silica loading increases from zero to 8 wt. $\%$. However, ethanol permeability significantly depends in fumed silica loading and decreases on $70 \%$ by increasing fumed silica loading from zero to 8 wt.\%. On the other hand, Henry law coefficients of both species increase with increasing fumed silica loading. Henry law coefficient of water increases about 10 times, while that of ethanol increases about 360 times by increasing fumed silica loading from zero to $8 \mathrm{wt} . \%$. In addition, modified thickness increases about 5 times for both components and this can be related to membrane swelling increment by increasing fumed silica loading [50]. 
By increasing fumed silica loading, ethanol permeation flux increases in both common and swollen portions of the membrane. Water permeation fluxes in these two portions have maximum and decrease afterward unless for the swollen portion at low temperatures which increases and never decreases throughout the experimental temperature range studied.

\section{Conclusion}

A composite membrane consists of a thin hydrophilic fumed silica loaded PVA layer coated on a tubular porous ceramic support was prepared. Prepared membranes were evaluated using ethanol pervaporation dehydration. Hydrophilic and cross-linked structure of the synthesized membranes resulted in high permeation flux and selectivity. A solution diffusion based mathematical model was developed to predict water and ethanol permeation fluxes through the membrane. Using this model, permeation flux and selectivity of different composite membranes operated at different conditions were evaluated. The distinctive features of the developed model can be summarized as follows:

- the model can predict permeation flux and selectivity with good accuracy $(\mathrm{RMSD}=$ $0.24)$

- the model is an explicit function of all operating parameters

- the model can predict effects of fumed silica loading

The results illustrate that by increasing temperature, water and ethanol permeabilities of the common and extremely swollen polymer and thus the entire permeability decrease while the Henry law coefficient of water and ethanol increase. Water and ethanol vapor pressures also increase with increasing temperature. Increasing water and ethanol fluxes can be related to the dominant effects of their Henry law coefficient and vapor pressures increment compared to their permeabilities. However, based on the model predictions, at high temperature, when the composite membrane is highly loaded with fumed silica, the dominant affective 
parameter changes to be water permeability and this leads to a maximum water permeation flux.

Increasing fumed silica loading decreases permeabilities, while increases Henry law coefficients of water and ethanol and the effective thickness of the membrane. Increasing $l_{\text {effective }}$ and decreasing $P_{\text {Wate }}^{G}$ and $P_{\text {Ethanol }}^{G}$ reversely affect permeation fluxes of species while increasing $H_{\text {Water }}^{G}$ and $H_{\text {Ethanol }}^{G}$ enhance permeation fluxes. As the dominant effects are increment of water and ethanol Henry law coefficients permeation fluxes of both components increase with increasing fumed silica loading. It should be noted that by increasing temperature, the superiority of $H_{\text {Water }}^{G}$ and $H_{\text {Ethanol }}^{G}$ diminishes and undesirable effects of $l_{\text {effective }}$ increment and $P_{\text {Water }}^{G}$ and $P_{\text {Ethanol }}^{G}$ reduction, which all lead to lower permeation performance, become dominant. Therefore, water permeation flux exhibits a maximum value at $6 \mathrm{wt} . \%$ fumed silica loading.

\section{Acknowledgment}

The financial support of Iran National Science Foundation (INSF) is warmly appreciated.

\section{References}

[1] T.J. Benson, C.E. George, Cellulose Based Adsorbent Materials for the Dehydration of Ethanol Using Thermal Swing Adsorption, Adsorption 11 (2005) 697-701.

[2] A. Chianese, F. Zinnamosca, Ethanol dehydration by azeotropic distillation with a mixed-solvent entrainer, The Chemical Engineering Journal 43 (1990) 59-65.

[3] V. Gomis, R. Pedraza, O. Francés, A. Font, J.C. Asensi, Dehydration of Ethanol Using Azeotropic Distillation with Isooctane, Industrial \& Engineering Chemistry Research 46 (2007) 4572-4576.

[4] E.L. Ligero, T.M.K. Ravagnani, Dehydration of ethanol with salt extractive distillation-a comparative analysis between processes with salt recovery, Chemical Engineering and Processing: Process Intensification 42 (2003) 543-552.

[5] A. Meirelles, S. Weiss, H. Herfurth, Ethanol dehydration by extractive distillation, Journal of Chemical Technology \& Biotechnology 53 (1992) 181-188.

[6] P.D. Chapman, T. Oliveira, A.G. Livingston, K. Li, Membranes for the dehydration of solvents by pervaporation, Journal of Membrane Science 318 (2008) 5-37. 
[7] Y. Huang, P. Zhang, J. Fu, Y. Zhou, X. Huang, X. Tang, Pervaporation of ethanol aqueous solution by polydimethylsiloxane/polyphosphazene nanotube nanocomposite membranes, Journal of Membrane Science 339 (2009) 85-92.

[8] A. Shariati, M. Omidkhah, M.Z. Pedram, New permeation models for nanocomposite polymeric membranes filled with nonporous particles, Chemical Engineering Research and Design 90 (2012) 563-575.

[9] S.-L. Wee, C.-T. Tye, S. Bhatia, Membrane separation process-Pervaporation through zeolite membrane, Separation and Purification Technology 63 (2008) 500-516.

[10] Y. Zhu, S. Xia, G. Liu, W. Jin, Preparation of ceramic-supported poly(vinyl alcohol)-chitosan composite membranes and their applications in pervaporation dehydration of organic/water mixtures, Journal of Membrane Science 349 (2010) 341-348.

[11] H. Zou, S. Wu, J. Shen, Polymer/Silica Nanocomposites: Preparation, Characterization, Properties, and Applications, Chemical Reviews 108 (2008) 3893-3957.

[12] F. Xiangli, Y. Chen, W. Jin, N. Xu, Polydimethylsiloxane (PDMS)/Ceramic Composite Membrane with High Flux for Pervaporation of Ethanol-Water Mixtures, Industrial \& Engineering Chemistry Research 46 (2007) 2224-2230.

[13] G. Liu, W. Wei, W. Jin, N. Xu, Polymer/Ceramic Composite Membranes and Their Application in Pervaporation Process, Chinese Journal of Chemical Engineering 20 (2012) 62-70.

[14] W. Wei, S. Xia, G. Liu, X. Dong, W. Jin, N. Xu, Effects of polydimethylsiloxane (PDMS) molecular weight on performance of PDMS/ceramic composite membranes, Journal of Membrane Science 375 (2011) 334-344.

[15] G. Liu, F. Xiangli, W. Wei, S. Liu, W. Jin, Improved performance of PDMS/ceramic composite pervaporation membranes by ZSM-5 homogeneously dispersed in PDMS via a surface graft/coating approach, Chemical Engineering Journal 174 (2011) 495-503.

[16] H. Matsuda, H. Yanagishita, H. Negishi, D. Kitamoto, T. Ikegami, K. Haraya, T. Nakane, Y. Idemoto, N. Koura, T. Sano, Improvement of ethanol selectivity of silicalite membrane in pervaporation by silicone rubber coating, Journal of Membrane Science 210 (2002) 433-437.

[17] R. Xu, G. Liu, X. Dong, Wanqin, Jin, Pervaporation separation of n-octane/thiophene mixtures using polydimethylsiloxane/ceramic composite membranes, Desalination 258 (2010) 106-111.

[18] Y. Ki Hong, W. Hi Hong, Influence of ceramic support on pervaporation characteristics of IPA/water mixtures using PDMS/ceramic composite membrane, Journal of Membrane Science 159 (1999) 29-39.

[19] W. Yoshida, Y. Cohen, Ceramic-supported polymer membranes for pervaporation of binary organic/organic mixtures, Journal of Membrane Science 213 (2003) 145-157.

[20] S. Xia, X. Dong, Y. Zhu, W. Wei, F. Xiangli, W. Jin, Dehydration of ethyl acetate-water mixtures using PVA/ceramic composite pervaporation membrane, Separation and Purification Technology 77 (2011) 53-59.

[21] J.-D. Jou, W. Yoshida, Y. Cohen, A novel ceramic-supported polymer membrane for pervaporation of dilute volatile organic compounds, Journal of Membrane Science 162 (1999) 269284.

[22] A.K. Pabby, S.H. Rizvi, A.M. Sastre, Handbook of membrane separations: chemical, pharamaceutical, food, and, biotechnological applications, CRC Press, New York, 2009.

[23] E. Cséfalvay, Z. Szitkai, P. Mizsey, Z. Fonyó, Experimental data based modelling and simulation of isopropanol dehydration by pervaporation, Desalination 229 (2008) 94-108.

[24] P. Gómez, R. Aldaco, R. Ibáñez, I. Ortiz, Modeling of pervaporation processes controlled by concentration polarization, Computers \& Chemical Engineering 31 (2007) 1326-1335.

[25] K. Koch, A. Górak, Pervaporation of binary and ternary mixtures of acetone, isopropyl alcohol and water using polymeric membranes: Experimental characterisation and modelling, Chemical Engineering Science 115 (2014) 95-114.

[26] A. Lovasz, T. Farkas, P. Mizsey, Methodology for modelling of pervaporation: step from binary to ternary mixtures, Desalination 241 (2009) 188-196.

[27] A. Mafi, A. Raisi, M. Hatam, A. Aroujalian, A mathematical model for mass transfer in hydrophobic pervaporation for organic compounds separation from aqueous solutions, Journal of Membrane Science 423-424 (2012) 175-188. 
[28] M. Rezakazemi, S. Razavi, T. Mohammadi, A.G. Nazari, Simulation and determination of optimum conditions of pervaporative dehydration of isopropanol process using synthesized PVAAPTEOS/TEOS nanocomposite membranes by means of expert systems, Journal of Membrane Science 379 (2011) 224-232.

[29] N. Valentínyi, E. Cséfalvay, P. Mizsey, Modelling of pervaporation: Parameter estimation and model development, Chemical Engineering Research and Design 91 (2013) 174-183.

[30] C.K. Yeom, R.Y.M. Huang, Modelling of the pervaporation separation of ethanol-water mixtures through crosslinked poly(vinyl alcohol) membrane, Journal of Membrane Science 67 (1992) 39-55.

[31] H.K. Lonsdale, U. Merten, R.L. Riley, Transport properties of cellulose acetate osmotic membranes, Journal of Applied Polymer Science 9 (1965) 1341-1362.

[32] R. Krishna, J.A. Wesselingh, The Maxwell-Stefan approach to mass transfer, Chemical Engineering Science 52 (1997) 861-911.

[33] M. Fels, R.Y.M. Huang, Diffusion coefficients of liquids in polymer membranes by a desorption method, Journal of Applied Polymer Science 14 (1970) 523-536.

[34] T. Kataoka, T. Tsuru, S.-i. Nakao, S. Kimura, Permeation Equations Developed for Prediction of Membrane Performance in Pervaporation, Vapor Permeation and Reverse Osmosis Based on the Solution-Diffusion Model, JOURNAL OF CHEMICAL ENGINEERING OF JAPAN 24 (1991) 326333.

[35] T. Okada, T. Matsuura, A new transport model for pervaporation, Journal of Membrane Science 59 (1991) 133-149.

[36] J.G. Wijmans, R.W. Baker, A simple predictive treatment of the permeation process in pervaporation, Journal of Membrane Science 79 (1993) 101-113.

[37] J.-J. Shieh, R.Y.M. Huang, A Pseudophase-Change Solution-Diffusion Model for Pervaporation. I. Single Component Permeation, Separation Science and Technology 33 (1998) 767-785.

[38] M.S. Ray, Diffusion in Zeolites and Other Microporous Solids, by J. Karger and D. M. Ruthven, John Wiley, New York, USA (1992). 605 pages. ISBN 0-47 1-50907-8, Developments in Chemical Engineering and Mineral Processing 4 (1996) 254-254.

[39] M.H.V. Mulder, C.A. Smolders, On the mechanism of separation of ethanol/water mixtures by pervaporation I. Calculations of concentration profiles, Journal of Membrane Science 17 (1984) 289307.

[40] M. Abbasi, M. Mirfendereski, M. Nikbakht, M. Golshenas, T. Mohammadi, Performance study of mullite and mullite-alumina ceramic MF membranes for oily wastewaters treatment, Desalination 259 (2010) 169-178.

[41] S.J. Lue, D.-T. Lee, J.-Y. Chen, C.-H. Chiu, C.-C. Hu, Y.C. Jean, J.-Y. Lai, Diffusivity enhancement of water vapor in poly(vinyl alcohol)-fumed silica nano-composite membranes: Correlation with polymer crystallinity and free-volume properties, Journal of Membrane Science 325 (2008) 831-839.

[42] M. Samei, T. Mohammadi, A.A. Asadi, Tubular composite PVA ceramic supported membrane for bio-ethanol production, Chemical Engineering Research and Design 91 (2013) 2703-2712.

[43] O. Bakhtiari, M. Samei, H. Taghikarimi, T. Mohammadi, Preparation and characterization of mullite tubular membranes, Desalination and Water Treatment 36 (2011) 210-218.

[44] X. Feng, R.Y.M. Huang, Liquid Separation by Membrane Pervaporation: A Review, Industrial \& Engineering Chemistry Research 36 (1997) 1048-1066.

[45] Huang, R. YM., Pervaporation membrane separation processes, Elsevier Science Ltd1991.

[46] R.W. Baker, Membrane technology and applications, 2nd ed., McGraw-Hill, England, 2004.

[47] S.J. Lue, S.-J. Shieh, Modeling water states in polyvinyl alcohol-fumed silica nano-composites, Polymer 50 (2009) 654-661.

[48] V.M. Gun'ko, P. Pissis, A. Spanoudaki, V.I. Zarko, Y.M. Nychiporuk, L.S. Andriyko, E.V. Goncharuk, R. Leboda, J. Skubiszewska-Zięba, V.D. Osovskii, Y.G. Ptushinskii, Relaxation phenomena in poly(vinyl alcohol)/fumed silica affected by interfacial water, Journal of Colloid and Interface Science 312 (2007) 201-213.

[49] B.E. Poling, J.P.O. Prausnitz, The properties of gases and liquids, 5 ed., McGraw-Hill, New York, 2000.

[50] S. Ulutan, T. Nakagawa, Separability of ethanol and water mixtures through PTMSP-silica membranes in pervaporation, Journal of Membrane Science 143 (1998) 275-284. 


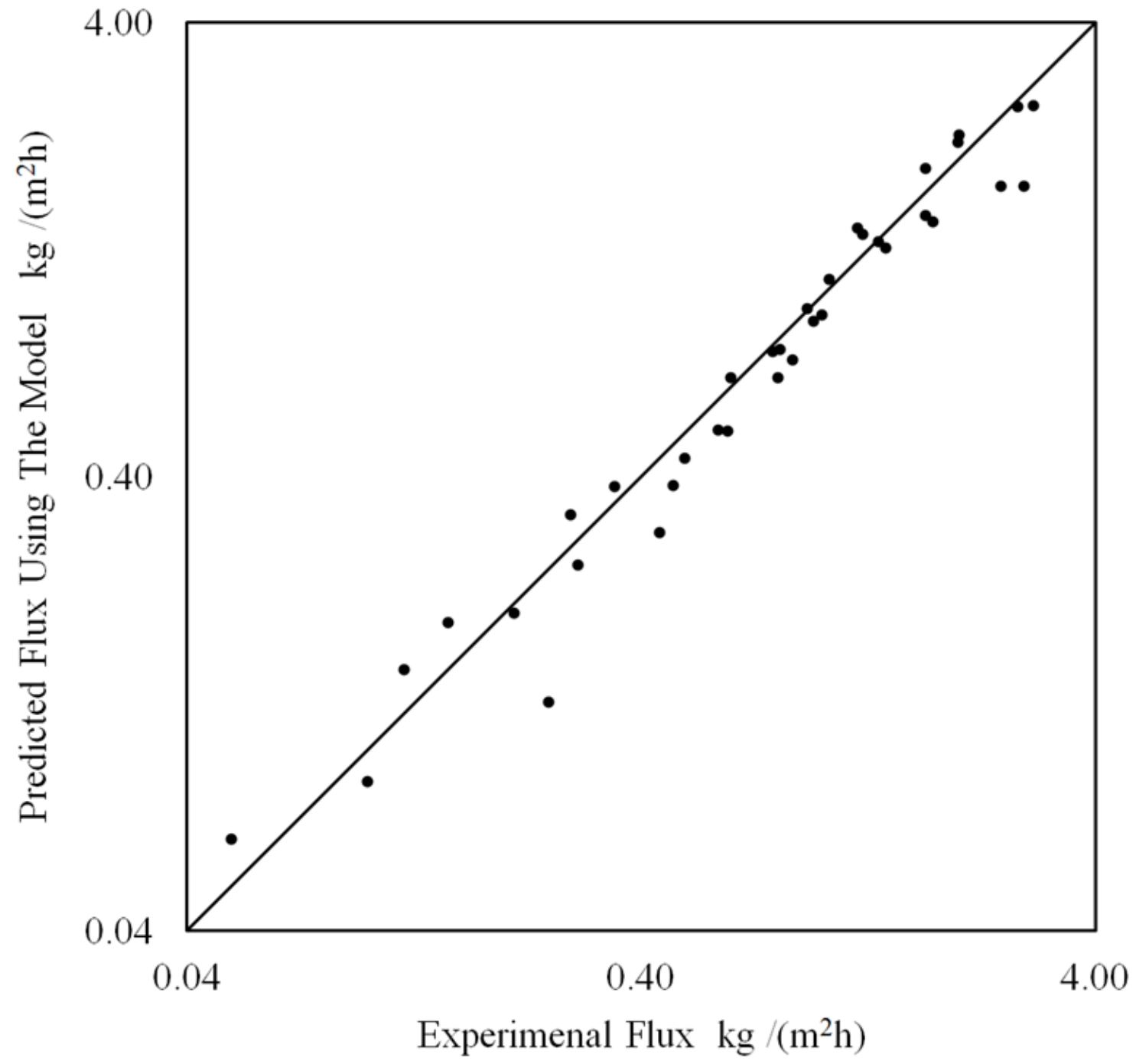

